\title{
"WHO WOULD HIRE A BLIND POET?" Blindness in the Eyes of Stephen Kuusisto
}

THE TROPE OF BLINDNESS HAS PERSISTED SINCE ANTIQUITY IN FIGURES LIKE OEDIPUS, TIRESIAS, AND THE HYPOTHETICAL BLIND MAN. FUTHERMORE, COLLOQUIAL USES OF BLINDNESS SHORE UP PROBLEMATIC AND REDUCTIVE NARRATIVES AND EXPECTATIONS ABOUT BLIND INDIVIDUALS. REPRESENTING THE DISABLED MAN THUS POSES A DISTINCT CHALLENGE AS IT WORKS AGAINST HEGEMONIC NOTIONS OF MASCULINITY AND ABILITY. DISABILITY—AS IT IS REDUCTIVELY ASSOCIATED WITH DEPENDENCY, INFIRMITY, AND WEAKNESS-CONTRADICTS THE STRENGTH, AUTONOMY, AND BODILY INTEGRITY OF STEREOTYPICAL MASCULINITY. THROUGH CLOSE READINGS OF THE POETRY AND MEMOIR OF STEPHEN KUUSISTO, A PARTIALLY BLIND AMERICAN POET, THE AUTHOR IDENTIFIES THE DOUBLE GESTURE OF DEFAMILIARIZATION AND REFAMILIARIZATION IN KUUSISTO'S REPRESENTATIONS OF BLINDNESS AND MASCULINITY. KUUSISTO CARVES OUT A SPACE FOR THE BLIND MAN IN EVERYDAY LIFE BY DEPLOYING, REWORKING, AND REJECTING THE PROBLEMATIC CONSTRUCTIONS OF BLINDNESS AND MASCULINITY. 
"At times the blind see light,

And that moment is the Sistine ceiling ..."

—Stephen Kuusisto, “Only Bread, Only Light”

Disability theorist Tom Shakespeare observes that the disabled man "is largely absent as the subject of research." Shakespeare is careful to cite the social model of disability to convey precisely where disability inheres: not in the body itself, but in the culture in which the body is located. What this allows then is an alliance with other critical discourses, such as the similar goals and methods of feminism and disability rights. If interrogating how the body is represented is crucial to critical feminist theory, the two discourses converge precisely at the body. What most concerns Shakespeare is the absence of narratives concerning men with disabilities and the ways in which differences in disability-between men and women, most specificallyare elided. In ableist and patriarchal cultures, disability and masculinity are opposites; if stereotypical disability suggests infirmity or weakness, stereotypical masculinity connotes "strength, potency, and physical activity." ${ }^{2}$ Disabled masculinity, as a seemingly contradictory and incoherent subject position, resists expected or stereotypical narration and representation precisely because it unsettles the body and the language in which it is figured.

The blind man, however, has been a cultural mainstay for millennia, from the dramas and mythologies of ancient Greece to the films and novels of the contemporary United States. What is most troubling is that the blind man is still

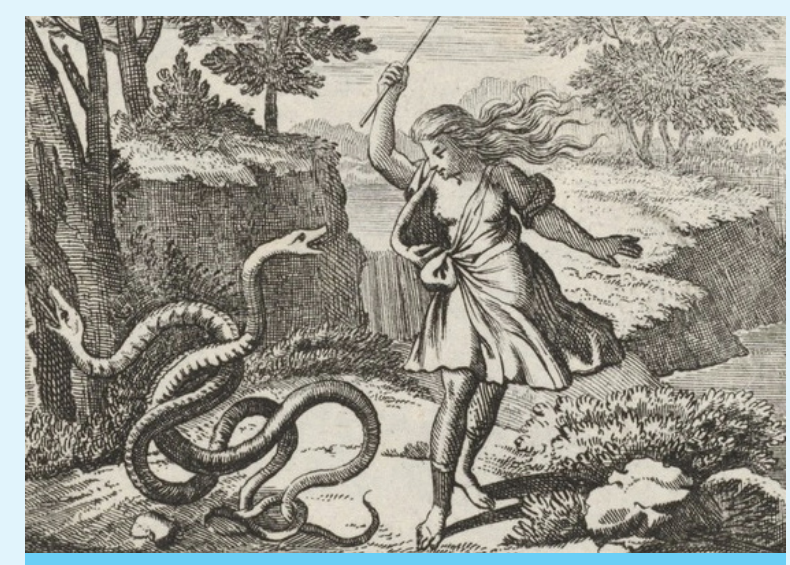

TIRESIAS, A GREEK MYTHOLOGICAL PROPHET, IS TURNED INTO A WOMAN AFTER STRIKING SNAKES. (COURTESY OF WIKIMEDIA COMMONS) largely "in Oedipus' shadow." 3 Representations of blindness, reiterated over time, all carry the traces of the infamous blind figures of antiquity: Oedipus and Tiresias.4.5 This inability to break with the past has constrained, to an extent, the contemporary blind man. For Sigmund Freud, the tragedy of Oedipus has "left ineradicable traces in the history of humanity" precisely because he exemplifies the universality of his desires, crimes, and guilt of Oedipus. ${ }^{6}$ Blindness is the punishment Oedipus inflicts upon himself for his wretched deeds, charging blindness with enormous moral significance. Although the connection between blindness and sin may predate the legend, the representation of Oedipus renders "the sin distressingly and memorably specific." 7 This single blind figure's tendency to haunt the blind, man and woman alike, is evidence of the persistence and prominence of Greek drama. Where in Ancient Greece, performance and recitation of Oedipus converged "religion, morals, society, and art" in the narrative of Oedipus, its retelling and appropriation throughout history has fixed Oedipus as a prominent cultural figure of blindness. ${ }^{8}$

The other "renowned story about blindness" arises from Greek tragedy, too, in the figure of Tiresias. ${ }^{9}$ The body of Tiresias is transgressive: he has been both man and woman. What further mars his body is the blindness with which Hera punishes him. Here Oedipus and Tiresias align in the association of blindness and punishment. What elides this physical blindness, however, is his mystical foresight. Zeus bestows upon Tiresias the "power of prophecy," and any perceived lack is diminished by "the magic of his gift". ${ }^{\text {10 }}$ If one regards Tiresias in the shadow of Oedipus, what is most remarkable is the "ecstasy, grace, astonishment, instinct, hallucination, the soul" with which blindness is identified. ${ }^{\text {II }}$ Moreover, throughout the history of philosophy, another visually impaired figure emerges: "the Hypothetical Blind Man." ${ }^{2}$ Although philosophers ventriloquize their "Hypothetical Blind Men," narrating their non-visual worlds and the wisdom to which they have access, the philosophers often deploy them only to emphasize "the importance of sight and to elicit a frisson of awe and pity." ${ }^{13}$ The Hypothetical Blind Man's own body is deployed against itself; his body is always subordinated to the abled man.

Two opposed connotations of blindness emerge then from history: blindness as punishment and blindness as blessing. Oedipus and Tiresias are perhaps the first-and thus the most recognizable-characters with blindness in the Western tradition. What the recurring deployment of vi- 


\section{"Disability life-writing is able to re-create language precisely because its subject ... uses ordinary language to challenge conventions, stereotypes, and misrepresentations of disability."}

sual impairment in various discourses-literary, cultural, social-facilitates is the making of blindness into metaphor, allegory, or narrative device. In fact, the literary and cultural narratives in which blind characters figure prominently often depend on visual impairment as "narrative prosthesis." I4 Disability becomes narrative prosthesis precisely when it is figured as "a destabilizing sign of cultural prescriptions about the body and a deterministic vehicle for the characterization for characters constructed as disabled." ${ }^{15}$ Characters marked as "disabled" become the very impetus for the narratives themselves; in this way, the disabled bodies of Oedipus and Tiresias become "key compo-

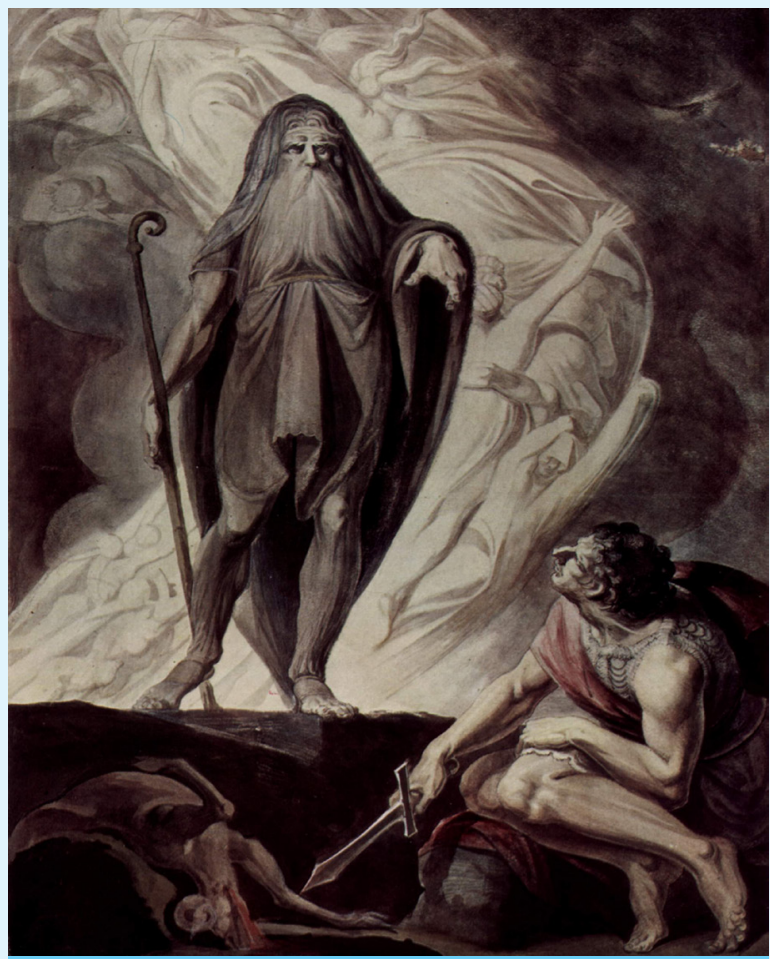

TIRESIAS APPEARING TO THE HERO ULYSSES (COURTESY OF WIKIMEDIA COMMONS) nents of the plot" of their myths as they are positioned in contrast to the nondisabled characters. ${ }^{16}$ Both Oedipus and Tiresias "[oscillate] between micro and macro levels of metaphorical meaning supplied by disability;" their bodies are simultaneously private and public, fraught with personal and sociocultural significance. ${ }^{17}$ What is so problematic about these narratives is the use of blindness chiefly as a plot device, rather than an instance of bodily difference or individual, lived experience.

Strangely, it is this movement between registers of meaning that restricts the blind man in literature and culture. His visual impairment is repeatedly deployed time and again for social and moral purposes; his blindness is allegorized as either punishment or blessing. The blind man's body both spoken for and written for is constrained within "a limited array of symbolic meanings." ${ }^{18}$ Although blindness mars the man as deviant, narrative prosthesis renders his body docile through its compliance to and reiteration of stereotypes of disability. Representing blindness recalls the characters of the blind men of the Western cultural tradition and the contradictory and reductive characterizations and connotations of blindness throughout history. The blind man's story is perceived as always already written or vocalized; on his body the cultural narrative of blindness is always already inscribed. ${ }^{19}$

To move from the shadows of Oedipus, Tiresias, and the Hypothetical Blind Men, the blind man must represent himself. In order for bodily impairment to be recognized not as deviance, but as difference, it is crucial for self-representation to address the "everyday phenomenon" of lived disability. ${ }^{\circ}$ Writing with blindness and about blindness, while both employing and transgressing conventions of disability, will propose "blindness as something besides the absence of sight." ${ }^{21}$ Self-representation of disability is both a response to and a reaction against "the traditional misrepresentation of disability in Western culture." ${ }^{22}$ Disability-in this case, blindness - typically irrupts into the narrative as a mark of otherness, of deviance. To alleviate 
i the anxiety of otherness and deviance, both the narrative and the reader prompt the blind man to explain away his blindness. These narratives anticipate the blind man's "[conformity] to, and thus [confirmation of], a cultural script" of blindness. ${ }^{23}$ This implicit subordination of the disabled body to the abled body is precisely what disability life-writing contests.

Language is precisely what enables the progressive and positive possibilities of disability life-writing. This claim, in part, is predicated upon the iterability of signs posited by Jacques Derrida: each sign, he asserts, is repeatable, "communicable, transmittable, decipherable."24 Insofar as each sign is invested with meaning by its writer, its speaker, the sign carries with it "a force that breaks with its context." ${ }^{25}$ Each sign is not restricted to a single, conventional meaning; there is, instead, a limitless possibility for meaning in each sign. In disability life-writing, then, that progress is only possible through the transgression of expected meaning. The disabled body is able to sign against the ableist culture and the hegemony of the abled; in this way, the body's transgressive potential can be realized. Disability life-writing is able to re-create language precisely because its subject-the disabled body and its experienceuses ordinary language to challenge conventions, stereotypes, and misrepresentations of disability.

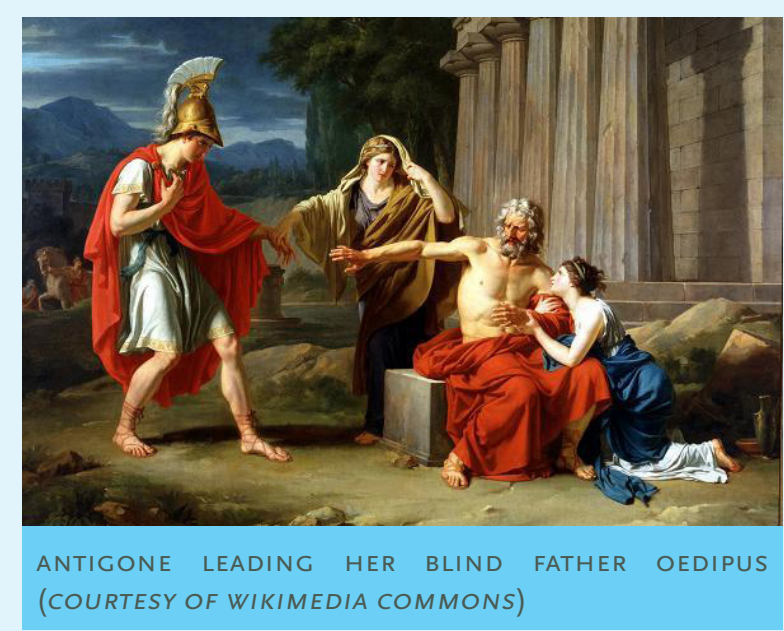

In disability culture, poetry holds the greatest potential for realizing the "infinite possibilities embedded within ordinary language." ${ }^{26}$ While "ordinary language" follows a certain grammar and utilizes expected denotations and connotations, poetic language departs from these conventions.
Poets break open syntax and grammar to generate new meanings; the movement of poetry follows an associative rather than a grammatical logic. "Ordinary language" makes meaning in time, in the sequential order of the words, whereas poetry relies on spatial, associative links between the words and images of the poem. In a sense, poetry "breaks the inertia of language-habits." ${ }^{27}$ When the subject of poetry is disability, the content of the poem breaks convention as much as the form itself. The poetics of disability, it seems, would emphasize the transgressive and generative possibilities of language and the body. While ableist societies typically isolate people with disabilities through cultural practices, traditions, and institutions, the reclamation of "ordinary language" by disability culture poetry relocates people with disabilities "in the normal ... in the everyday." ${ }^{28}$

Thus, what is crucial to the poetry of disability culture is this re-presentation and representation of the disabled subject, such as the aforementioned blind man, who has inhabited literary and cultural narratives now for millennia. To bring himself into the light from the shadow of Oedipus, he must represent himself. In an ableist society, the disabled male is an entirely incoherent subject position. Hegemonic standards of masculinity-among them, "initiative, competitiveness, self-control, assertiveness, and independence" - invalidate disabled masculinity, relegating the disabled male to a powerless position. ${ }^{29}$ For the patriarchal and ableist traditions and institutions to strip power from the body and the voice of the disabled male, his body's signs of deviancy must be erased. What always remains, however, are the marks of difference and impairment in which the power of the disabled subject position resides. The disabled body never ceases to sign against the ableist culture that subdues it.

In this sense, the poetry of the blind man has the potential to reshape reductive and widespread standards of masculinity and to create space for the disabled male in the live world. For Stephen Kuusisto, a partially blind poet himself, to write is to eclipse a tradition of shadows. Kuusisto was born in March I955 with "retinopathy of prematurity," and has been considered "legally blind" since childhood. ${ }^{\circ}$ Moving from the myth-worlds of Oedipus and Tiresias, from the powerless place of the disabled man, Kuusisto positions himself "in the normal ... in the everyday." ${ }^{31}$ Understanding disability as a "generative experience" in the production of poetry recognizes language's enormous power to "[rewrite] conventional standards of poetic beauty, form, and value." ${ }^{2}$ 


\section{"For Stephen Kuusisto, a partially blind poet himself, to write is to eclipse a tradition of shadows."}

Crucial to understanding disability as an aesthetic or literary practice is acknowledging its political potential. If aesthetics is concerned with "[tracking] the sensations that some bodies feel in the presence of other bodies," the aesthetics of disability culture poetry can, in fact, produce change in the corporeal world. ${ }^{33}$ Kuusisto's memoir and poetry collections figure blindness as an everyday experience, rather than an extraordinary, mythical experience. Here, Kuusisto begins to move himself from the shadow of Oedipus.

To produce its aesthetic effects, poetry dislocates language from its expected meaning. Disability culture poetry, however, is charged with the additional task of dissolving the entrenched cultural representations of disability that limit and reduce the true representation of disability. To create his world with words, Kuusisto must first depart from a culture and a language that disavow blindness. Kuusisto accomplishes this in the first line of his memoir, Planet of the Blind: "Blindness is often perceived by the sighted as an either/or condition: one sees or one does not." 34 What follows his explanation of his vision as "[staring] at the world through smeared and broken windowpanes," is a mythic description of his impaired eyesight. ${ }^{35}$ In the colors and shapes of his visual field, he sees "sails of Tristan's ship," "the great dead Greek's in Homer's descriptions of the underworld." ${ }^{36}$ Although this description positions him squarely in the mythic world of Oedipus and Tiresias, his introduction does not suggest the opposite connotations of these blind Greek men. He is neither sinner nor seer; rather, he seems entirely ordinary. Although the mythic past, populated with the traditional and hypothetical blind men, colors his vision, it does not dominate it. In fact, Kuusisto's vision seems to meld the legendary with the ordinary: for example, who he perceives as one of "the great dead Greek ... crossing Charon's river" is only "a middle-aged man in a London Fog raincoat." 37

This oscillation between the mythic or traditional past and the everyday present is emblematic of Kuusisto's memoir and corpus of poetry. In fact, the first group of poems, "Blind Days in Early Youth," in his collection Only Bread, Only Light is reminiscent of the first page of his memoir. This first group, which speaks to his early fascination with vision and blindness, is divided into three separate poems: "No Name for It," "Terra Incognita," and "Awake All Night." ${ }^{8}$ Where in Planet of the Blind, Kuusisto conjures up the myths of ancient Greece, in the first collection of Only Bread, Only Light, he invokes the Scandinavian culture in which he was raised.

Although Kuusisto was born in Exeter, New Hampshire, his family moved to Finland for his father's job. ${ }^{39}$ In his earliest memories looms the imposing figure of "a severe old woman who speaks to [his] father in Finland's brand of Swedish." ${ }^{\circ 0}$ She reappears in the first poem of the subsection, "No Name for It," as "the Swedish matron" who chides the speaker, the young Kuusisto. ${ }^{4 \mathrm{I}}$ The poem's title immediately calls attention to language's limitations: there is "no name" for an unidentified "it." In a childlike manner, the young Kuusisto rattles off a few words"something Swedish:" "rus-blind," "blinda-fläcken," "blind-pipa," "barna-blind." 42 Although he demonstrates a certain level of mastery of language by translating each of these idioms, there is something tentative and uncomfortable in his tone. The way in which these phrases are made by affixing "blind" unsettles Kuusisto precisely because the idioms have negative connotations- "blind drunk" and "nonentity," for instance. ${ }^{43}$

What most troubles Kuusisto, however, is the "piety and reproof" of the Swedish matron's words: "En blind höna hittar också ett korn." 44 The translation of this line- "The fool's arrow sometimes hits the mark"-arrives only after a line break. ${ }^{45}$ The translation for the other idioms immediately follows the Swedish phrase, but the translation of the matron's derisive remark occurs in an entirely different couplet. This break conveys the dissonance of the speaker, trying to make sense of his own blindness and these blind-idioms. Her words reverberate in his mind, but her other call_—"barna-blind; "blind child'” —-"[echoes] on the stairs." ${ }^{46}$ While the translations are univocal and direct at the beginning of "No Name for It," the translations are opened to different interpretations. In fact, Kuusisto reiterates "barna-blind" only to alter his original translation as "blind from birth." 47

At the poem's conclusion, Kuusisto retranslates the Swedish matron's words: “En blind höna hittar... / The blind 
9 child's arrow..." ${ }^{48}$ Finally he takes control-albeit tentatively-of language; "blind" comes to signify not "fool," but only "blind" itself. Although this translation seems tautological, it gives Kuusisto incredible power to rend blindness from its idiomatic usages. He makes sense of blindness by experience, rather than the idioms inscribed in language that is not even his own. If "the fool's arrow sometimes hits the mark," here "the blind child's arrow" has hit the mark, however tentatively or elliptically. The poem becomes an "exploration of the possibilities of language" insofar as the young Kuusisto eschews the conventions of language, of meaning; idioms are evidence of the "inertia of language-habits" which poetry must overcome. ${ }^{49}$ Poetry is precisely the force that sets language into motion again, that moves the blind-man from the shadow of Oedipus, this blind-child from the shadow of idioms.

Furthermore, "No Name for It" departs from poetry's traditional reliance on the visual to accomplish its aesthetic effects. Instead, the poem employs auditory language more often-and, arguably, more forcefully-than does visual imagery. In fact, the visual is often overwhelmed by the auditory effects of language. It is not the image of the Swedish matron "[pointing] with a cane," for instance, that controls the poem; in fact, Kuusisto describes her appearance only vaguely..$^{\circ}$ Rather, her voice is what Kuusisto remembers most clearly; he recalls with acuity her "tone mixed with piety and reproof." 5 As her voice "echoed on the stairs" all those years ago, so now does it reverberate in the Swedish idioms throughout "No Name for It." ${ }^{2}$

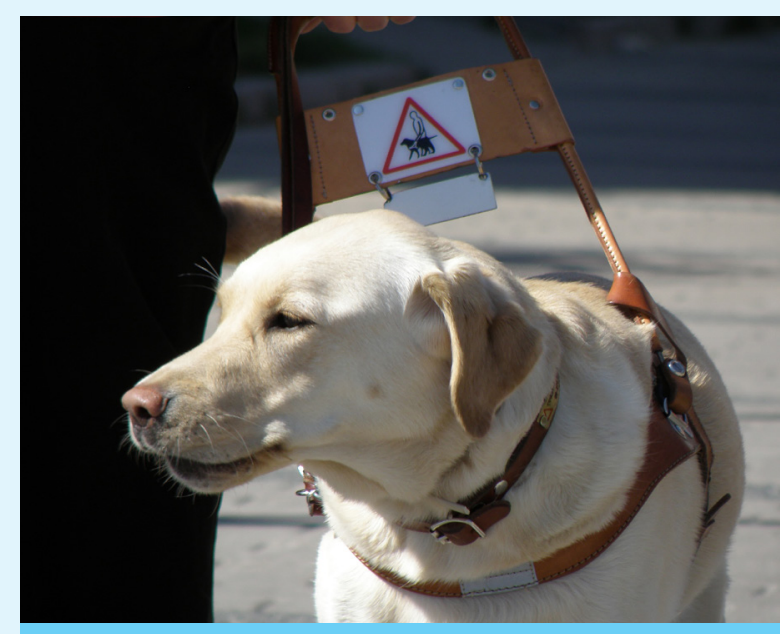

A SEEING-EYE DOG (COURTESY OF WIKIMEDIA COMMONS)
This reliance on the auditory, however, must not be construed as a domination of the auditory over the other senses. His poetry does not merely reverse the pervasive "belief that human experience, both physical and mental, is essentially visual." 53 As Michael L. Melancon notes in his critical study of Only Bread, Only Light, Kuusisto's poetry often investigates "how sight, hearing, and touch can serve to facilitate expression and communication by both receiving information and transmitting information." ${ }^{54}$ In this way, Kuusisto does not exchange visual primacy for auditory or tactile primacy. What emerges in his poetry is a synergy of the senses in which perception and experience is not restricted to a single sense, a single meaning. If the first poem in "Blind Days in Early Youth" seems to suggest auditory primacy, the two poems collected with "No Name for It" deny this interpretation in favor of this syncing of the senses.

In fact, the auditory is what is absent from "Terra Incognita." The poem is remarkably visual and tactile: Kuusisto "[makes his way] among patches of dew - / Those constellations on the darkened grass." ened yard, he fathoms the dewdrops into constellations; here the "darkened grass" is illuminated by the stellar qualities of dew..$^{6}$ Just as the cosmic and the terrestrial are united here, so too are the visual and the tactile. The perceived movement of Kuusisto across the grass and the vision of the dewdrops are inseparable. The play of light and dark emerges again in the final stanza: "I pictured a shirt - / How I'd pull it over my head / And vanish in the sudden light." 57 The stanza is initially coherent, describing the tactility of putting on a shirt; the body moves in a familiar, expected manner. What is so peculiar, however, is the way in which he imagines "[vanishing] in sudden light." ${ }^{8} 8$ If light connotes knowledge or presence, disappearing "in sudden light" seems utterly incoherent. ${ }^{59}$ The final stanza describes a liminal moment, between the shirt being both on and off Kuusisto's body. Light and sight alone cannot confirm his body's corporeality; rather it is the position and motion of his body that remain as he "[pulls the shirt] over [his] head." ${ }^{60}$ Vision and tactility are represented here in tandem, as the body cannot separate the two senses.

The synergy of the visual, the tactile, and the auditory emerges in the third poem of the first collection, "Awake All Night." In the first three couplets, Kuusisto establishes the presence of all three senses: "The cabinet radio glowed / With its lighted dial / As I pressed my face to the glass." 6 r Enamored by the light and the sound the radio produces, he draws it near, touching his face to the cabinet. Describ- 
ing his own glasses as "kaleidoscopes of light," he identifies his vision as both beautiful and impaired. ${ }^{62}$ This impairment, however, does not deny the possibility of enjoying "the brilliant city of tubes / Just visible through a crevice." "What he does, instead, is "lean close" to the radio cabinet; the intimacy of the young Kuusisto and the radio illustrates the inseparability of the senses. While blindness stereotypically connotes the impossibility of visual pleasure, "Awake All Night" establishes vision as a component of pleasure and everyday experience for the blind speaker.

In fact, the visual, the tactile, and the auditory all comprise pleasure and the everyday for Kuusisto, but the three senses are at once present and absent. Although he confesses that "[he] never heard the music" those nights, there in the radio is the promise, the remembrance of sound. ${ }^{64}$ Moreover, "[his] spectacles, thick as dishes," attempt to correct his partial blindness only to refract the light. ${ }^{65}$ The failure of his eyeglasses prompts him to "lean close," but he can only "[press his] face to the glass." ${ }^{\circ 6}$ What Kuusisto suggests in "Awake All Night" is the limitations of single-sense perception; his experience is not a matter of compensating for the senses. Rather, the poem makes evident the coordination of the senses. Pressed to the glass of the glowing radio cabinet, Kuusisto "looks down out of habit / at the vivid world." ${ }^{67}$ Living in the world, perceiving the world is a matter of the whole body, not a single sense. The synergy of vision, hearing, and touch anchors the body in the world, and it is this anchorage that allows Kuusisto to establish his everyday and to re-create in his poetry.

Kuusisto's poetry amounts to an attack on what David Bolt terms "the metanarrative of blindness," which is "the story in relation to which those ... who have visual impairments often find [themselves] defined." ${ }^{68}$ Crucial to understanding this narrative is acknowledging that it is inflected by "ocularcentrism," which "denotes a perspective-and by extension, a subject position-that is dominated by vision." ${ }^{\prime 9}$ This perspective is problematic precisely because it employs reductive, stereotypical representations of blindness to comprehend and convey the experience of blindness. What is more troubling is the exclusion of people with visual impairments from the weaving of this story; here the voice of the visually impaired is absent. In this way, the metanarrative misrepresents blind experience precisely by reproducing tropes of the Hypothetical Blind Men and the blind beggars by conjuring up the figures of
Oedipus and Tiresias. ${ }^{70}$ The traditions and narratives inscribed in an ableist and certainly, an ocularcentric culture perpetuate "ocularnormativism," which establishes vision as "the supreme means of perception." ${ }^{1}$

Although ocularcentrism textures the metanarrative of blindness with diverse and disdainful representations of visual impairment, I am concerned primarily with the thread of blindness and psychoanalysis. Freud revives Oedipus for his own thesis of man's natural ambivalence between love and aggression in Totem and Taboo, but blindness and the eyes also figure prominently, in his studies on the significance of dreams. ${ }^{72}$ In fact, Freud's The Interpretation of Dreams demonstrates the intense "interest in eye symbolism of psychoanalysis." 73 Recurring in psychoanalytic works are the associations of "testicular, ocular, and penile images," which establishes a link between masculinity, sexuality, and vision..$^{74}$ Bolt describes this fixation as "opthalmocentric," which privileges "the instrument of vision, as in notions of eyes." Opthalmocentrism is predicated upon ocularcentrism, linking inextricably vision and the eyes, and thus the association phallic imagery and eyesight implicitly genders the ability to gaze as masculine.

Building on the "implicit blindness-castration synonymy" of psychoanalytic theory, Rosemarie Garland-Thomson asserts "the social role of men is to be starers." 76,77 This proposition reflects "the gendered asymmetries of the patriarchy," which position males and females at opposite sides of the seer-seen dyad. ${ }^{78}$ Although the gendered implications of the vision only arise in "lived gendered relations," there is no doubt that "looking masculinizes... and being looked at feminizes." 79 This is precisely the precondition for the construction of the "male gaze," which, with a mere glance, subordinates the object of the stare.$^{80}$ In this way, the eyes are constructed as a synecdoche for the male body; thus the blind man, unable to exercise the male gaze, is emasculated.

This interrogation of ocularcentrism and opthalmocentrism again conveys the primacy assigned to vision, but what is at stake in the "blindness-castration synonymy" is sexuality itself. ${ }^{{ }_{1}}$ If the male gaze-and, by association, male sexuality-is predicated upon dominance, power, and inequality, the blind male gaze disassembles the hegemonic expectations and diffuses power. ${ }^{82}$ Visual impairment may render the blind man incapable of executing "normative masculine performances," but this does not necessarily emasculate him. ${ }^{{ }^{3}}$ Disabled men do not dis- 


\section{"It is not simply visual pleasure that Kuusisto achieves, but a wholly corporeal, holistic pleasure."}

avow masculinity and sexuality altogether; instead, the lived experience of disability and masculinity requires the blind man to renegotiate sexuality and gender. This revision of expected gender performances can, in turn, level the inequality of the masculine-feminine binary undergirding both patriarchal and ableist traditions.

Stephen Kuusisto's account of his first sexual experience in his memoir, Planet of the Blind, instantiates this negotiation of disability and masculinity. Although he had been "raised to know [he] was blind but taught to disavow it," Kuusisto stops masking his visual impairment in college. ${ }^{84}$ His professors accommodate his limitations, and one "benevolent Shakespeare professor" even finds someone to read to him. ${ }^{85}$ Gradually "his habitual shyness around women" diminishes as Kuusisto connects with his peers. ${ }^{86}$ This newfound confidence undergirds Kuusisto's relationship with Bettina, an "altogether irreverent young woman, ... an Irish country girl with long, thrilling, unkempt hair"87 If hegemonic masculinity asserts the male's prerogative and female's submission, Bettina's initiation of Kuusisto's first sexual encounter reverses that binary. With "a potent kiss" she pulls Kuusisto to the floor and guides him. ${ }^{88}$

In this moment, Bettina's agency astounds Kuusisto"[he] can't believe how quickly she does it." 89 In fact, Bettina initiates and controls the encounter, "pulling down [his] pants," "loosening [her] own buttons." $9 \circ$ Although her initiative may be perceived as a moment of feminine domination, the tenderness of the moment suggests something entirely different. If vision and sexuality are conflated in ocularcentric conceptions of masculinity, this scene separates them. It is not simply visual pleasure that Kuusisto achieves, but a wholly corporeal, holistic pleasure. Kuusisto figures this experience as entirely natural, beautiful: "a birch tree at midsummer, the sunlight seeming to be above and inside her." ${ }^{\text {II }}$ Although the visual certainly constitutes part of pleasure for both Kuusisto and Bettina, it is the heightened tactility of the experience for Kuusisto that anchors this first sexual encounter. To resist locating pleasure solely in either sex, the scene alternates between descriptions of his body and her body. What's more, while their two bodies are entangled, Kuusisto is "looped in the loops of her hair." ${ }^{2}$ Their bodies remain separate although intertwined, and the ambiguity of who touches who dis- mantles any domination or control implicit in the sexual encounter. This claim is informed, in part, by MerleauPonty's assertion of "crisscrossing ... of the touching and the tangible" during a sexual encounter. ${ }^{93}$ This is perhaps a reduction of Merleau-Ponty's argument, but there seems to be something in his conception of the tactility that mitigates the perceived hostility, dominance of the touch. ${ }^{94}$

Kuusisto's lived experience demonstrates the insufficiency of ideals of embodied masculinity. Where patriarchal and ableist norms, echoing the metanarrative of blindness, locate masculinity largely in the visual, Kuusisto's disabled masculinity posits a corporeality, a masculinity of the body whole, of all the senses. If traditional masculinity is predicated on "initiative, competitiveness, self-control, assertiveness, and independence," disabled masculinity renegotiates these standards in accordance with the lived experience of bodily impairment. ${ }^{95}$ Furthermore, disabled masculinity denaturalizes the "naturalized relation between masculinity and power." ${ }^{6}$ In her critical study of alternative masculinities, "Female Masculinity," Judith Halberstam carves out a space for disabled masculinity in the repertoire of male subject-positions. Her critique of action films centers on the use of prosthetic extensions of the body "to extend masculinity." 97 Prosthetics-gadgets, guns, automobiles, for example-implicitly "undermine the [idealized] heterosexuality" of the male star of the action film, effectively creating a gap between the hegemonic ideals of standards of masculinity and its embodiment in the world. ${ }^{9^{8}}$ These prostheses, too, seem to subvert the idealized independence of hegemonic masculinity.

Prostheses are essential to Kuusisto's day-to-day lived experience, and his reserve of prostheses comprises more than merely eyeglasses. Corky, Kuusisto's guide dog, functions like a prosthetic, as she increases his mobility and capabilities in everyday life. However, Corky complicates is the traditional notion of prosthetic masculinity. The heroic male, star of the action flick, can function without his gadgets and weapons; the prostheses only supplement the hero's masculinity. ${ }^{99}$ Kuusisto's guide-dog, Corky, is essential to his everyday life; here, man quite literally depends on man's best friend. In fact, Corky becomes integral to Kuusisto's lived experience as a disabled man. Whereas the gadgets of the action flick star seem unnatural and re- 
sist incorporation into the body, Corky and Kuusisto "move as one, [although they] are more than that." ${ }^{\prime \prime 0}$

Nowhere is this dependency, this between Kuusisto and his guide-dog more evident than in "Guiding Eyes," a poem written for Corky in Only Bread, Only Light. His admiration is apparent from the stanza:

\section{It's been five years}

Since I was paired with this dog

Who, in fact, is more than a dog -

She watches for me. ${ }^{\text {Ior }}$

What follows is a description of "[their] twin minds [going] walking" in New York City. ${ }^{102}$ Kuusisto and Corky navigate the city's well-travelled paths and its landmarks in an unexpected and mythical manner. The tension between their separate bodies and their singular functioning prompts Kuusisto to call him and his guide-dog "a kind of centaur - / or maybe two owls / Riding the shoulders of Minerva." ${ }^{\text {Io3 }}$ The mythic association here depicts the pair not as impaired or lacking, but rather as legendary, as wise. When he "[supposes] they're scarcely whole," he seems to recognize the myth of wholeness inscribed in the body. ${ }^{104}$ This realization is hardly dismal, and Kuusisto's subtle joy is palpable when he observes:

\section{The centaur gathers \\ What passes from our flesh \\ Into the heart \\ Of animal faith. ${ }^{\text {105 }}$}

Kuusisto's impairment here does not signify a lack, but rather signifies a recognition of bodily difference. Kuusisto and Corky come to signify wholeness of their separate, distinct bodies, and the unity of guide-dog and the guided. If the everyday is about routine, about establishing a home in one's own space, Corky is integral to Kuusisto's everyday precisely because "she leads [him] home." ${ }^{\text {106 }}$

In a way, "Guiding Eyes" returns us to the mythical world, inhabited not only by the centaurs invoked by Kuusisto, but also by the oldest blind men of the Western cultural tradition. Kuusisto's poetry and memoir oscillate between the mythical and the everyday. If ableist and patriarchal cultures operate by othering the disabled male, this alienation immediately locates him outside the norm, outside conventional, everyday experience.

What is so remarkable about Kuusisto's quotidian representations of blindness is its ability to establish an "everyday life, [that is] the quintessential quality of taken-forgrantedness." ${ }^{\circ}$ o7 Writing the everyday-that which goes without notice-is essential precisely because it relocates him, a disabled male, in the everyday consciousness: he is not an Oedipus, a Tiresias, or a Hypothetical Blind Man. ${ }^{\text {.08 }}$ The disabled man, then, becomes present, familiar. $\mathrm{He}$ identifies himself as blind only to jettison the metanarrative of blindness, and only then is he to able to familiarize, for the abled reader, his everyday life. This is precisely what disability life-writing aims to do: to familiarize and legitimize the everyday experience of disability by shedding the mask of the metanarrative. In this way, everyday disability resembles, represents, and coincides with everyday life. As Kuusisto "[walks] / both bodily and ghostly," he and Corky retread the paths of New York City to establish their own everyday existences; they move with, not against, the city. ${ }^{109}$

What Kuusisto's life-writing amounts to is re-presentation of everyday life as a disabled man. Embodied, lived life depends on more than the visual for Kuusisto-and arguably for all humans. What Kuusisto rejects by familiarizing and legitimatizing the experience of blindness are the hegemonic standards of ableist masculinity. In this way, the oscillation between the mythic, the everyday, and the synergy of the senses in Kuusisto's poetry and prose represents "disability and masculinity as lyric processes" that actively resist the "controlling narratives" of patriarchal and ableist culture. ${ }^{\text {IIO }}$ Representing disability and masculinity introduces an "unanticipated similarity between all things," thus establishing the everyday life and the embodied experience as "a holistic texture" of identities and sensory experience. ${ }^{\text {III }}$ Only now does Kuusisto move out of the shadows of Oedipus and illuminate his own everyday life as a blind male. 


\section{ENDNOTES}

I. Shakespeare, "The Sexual Politics of Disabled Masculinity," I999, 53.

2. Shakespeare, "The Sexual Politics of Disabled Masculinity,"

I999, 54 .

3. Kleege, Sight Unseen, I999, 63.

4. Kleege, Sight Unseen, I999, 66-69.

5. Kuusisto, Planet of the Blind, I998, I87.

6. Freud, Totem and Taboo, 1989, I92.

7. Kleege, Sight Unseen, 1999, 69.

8. Kleege, Sight Unseen, I999, I94.

9. Kuusisto, Planet of the Blind, I998, I87.

Io. Ibid.

II. Ibid.

I2. Kleege, "Blindness and Visual Culture: An Eyewitness

Account," 2013, 447.

I3. Kleege, "Blindness and Visual Culture: An Eyewitness Account," 2013, 448.

I4. Mitchell and Snyder, "Narrative Prosthesis," 20I3, 222.

I5. Mitchell and Snyder, "Narrative Prosthesis", 20I3, 224.

I6. Mitchell and Snyder, "Narrative Prosthesis," 20I3, 232. I7. Ibid.

I8. Mitchell and Snyder, "Narrative Prosthesis," 20I3, 234.

I9. Couser, "Disability, Life Narrative, and Representation," 2013, 458.

20. Couser, "Disability, Life Narrative, and Representation,"

20I3, 457 .

2I. Kleege, "Blindness and Visual Culture: An Eyewitness

Account," 2013, 453.

22. Couser, "Disability, Life Narrative, and Representation," 20I3,

457 .

23. Couser, "Disability, Life Narrative, and Representation," 2013 , 458 .

24. Derrida, “Signature Event Context,"I988, 8.

25. Derrida, "Signature Event Context," I988 9.

26. Bayliss, "Against Interpretosis: Deleuze, Disability, and

Difference," 2009, 289.

27. Ibid.

28. Bayliss, "Against Interpretosis: Deleuze, Disability, and

Difference," 2009292.

29. Shuttleworth, "Disabled Masculinity: Expanding the

Masculine Repertoire," 2004, I66.

30. Kuusisto, Planet of the Blind, I998, 6.

3I. Bayliss, "Against Interpretosis: Deleuze, Disability, and

Difference," 2009, 292.

32. Mintz, "Lyric Bodies: Poets on Disability and Masculinity,"

20I2, 248 .

33. Siebers, Disability Aesthetics, 2010, I.

34. Kuusisto, Planet of the Blind, I998, 5 .

35. Ibid.

36. Ibid.

37. Ibid.

38. Kuusisto, Only Bread, Only Light: Poems, 2000, 5-7.

39. Kuusito, Only Bread, Only Light: Poems, 2000, 5-7.

40. Kuusito, Only Bread, Only Light: Poems, 2000 , I0.
4I. Kuusito, Only Bread, Only Light: Poems, $2000,7$.

42. Kuusito, Only Bread, Only Light: Poems, 2000, I-3, 9.

43. Kuusito, Only Bread, Only Light: Poems, 2000, 2-3.

44. Kuusito, Only Bread, Only Light: Poems, 2000 , 4, Io.

45. Kuusito, Only Bread, Only Light: Poems, 2000, 5.

46. Kuusito, Only Bread, Only Light: Poems, 2000, 9, II.

47. Kuusito, Only Bread, Only Light: Poems, 2000, I2.

48. Kuusito, Only Bread, Only Light: Poems, 2000, I2-I3.

49. Bayliss, "Against Interpretosis: Deleuze, Disability, and

Difference," 2009, 292.

50. Kuusito, Only Bread, Only Light: Poems, 2000, 8.

51. Kuusito, Only Bread, Only Light: Poems, 2000 , Io.

52. Kuusito, Only Bread, Only Light: Poems, 2000, II.

53. Kleege, Sight Unseen, I999, 30.

54. Melancon, "A River that No One Can See," 2009 , I84.

55. Kuusito, Only Bread, Only Light: Poems, $2000,4$.

56. Kuusito, Only Bread, Only Light: Poems, 2000, 4.

57. Kuusito, Only Bread, Only Light: Poems, 2000 , II-I3.

58. Kuusito, Only Bread, Only Light: Poems, 2000, I3.

59. Ibid.

6o. Kuusito, Only Bread, Only Light: Poems, 2000, I2.

6I. Kuusito, Only Bread, Only Light: Poems, 2000, I-3.

62. Kuusito, Only Bread, Only Light: Poems, 2000, 5.

63. Kuusito, Only Bread, Only Light: Poems, 2000, 8-9.

64. Kuusito, Only Bread, Only Light: Poems, 2000 , IO.

65. Kuusito, Only Bread, Only Light: Poems, $2000,4$.

66. Kuusito, Only Bread, Only Light: Poems, 2000, 3, 6.

67. Kuusito, Only Bread, Only Light: Poems, 2000, I3-4.

68. Bolt, The Metanarrative of Blindness, 20I4, IO.

69. Bolt, The Metanarrative of Blindness, 20I4, I7.

70. Bolt, The Metanarrative of Blindness, 20I4, IO-II.

7I. Bolt, The Metanarrative of Blindness, 20I4, I4.

72. Freud, Totem and Taboo, I989, I92-4.

73. Bolt, The Metanarrative of Blindness, 20I4, 54.

74. Bolt, The Metanarrative of Blindness, 20I4, 56.

75. Bolt, The Metanarrative of Blindness, 20I4, 53.

76. Bolt, The Metanarrative of Blindness, 201456.

77. Garland-Thomson, Staring: How We Look, 2009, I46.

78. Garland-Thomson, Staring: How We Look, 2009, 4I.

79. Ibid.

8o. Ibid

8I. Bolt, The Metanarrative of Blindness: A Re-reading of

Twentieth-century Anglophone Writing, 57.

82. Shuttleworth, "Disabled Masculinity: Expanding the

Masculine Repertoire,” I66-I70.

83. Shuttleworth, "Disabled Masculinity: Expanding the

Masculine Repertoire," I67.

84. Kuusisto, Planet of the Blind, I998, 7.

85. Kuusisto, Planet of the Blind, 1998, 69.

86. Ibid.

87. Kuusisto, Planet of the Blind, I998, 70.

88. Ibid.

89. Ibid.

9o. Ibid.

9I. Kuusisto, Planet of the Blind, I998, 7I.

92. Ibid. 
93. Merleau-Ponty, "The Intertwining-The Chiasm." I968, I33. 94. Merleau-Ponty, "The Intertwining-The Chiasm," I968,

I33-4.

95. Shuttleworth, "Disabled Masculinity: Expanding the Masculine Repertoire," 2004, I66.

96. Halberstam, "An Introduction to Female Masculinity." I998, 2.

97. Halberstam, "An Introduction to Female Masculinity," I998,

98. Ibid

99. Halberstam, "An Introduction to Female Masculinity," I998, I- 5 .

I00. Kuusisto, Planet of the Blind, I998, Ioo.

IoI. Kuusito, Only Bread, Only Light: Poems, 2000 , I-4.

I02. Kuusito, Only Bread, Only Light: Poems, 2000, 5.

I03. Kuusito, Only Bread, Only Light: Poems, 2000, 8-10.

I04. Kuusito, Only Bread, Only Light: Poems,2000, I9.

I05. Kuusito, Only Bread, Only Light: Poems, 2000, 43-6.

Io6. Kuusito, Only Bread, Only Light: Poems, $2000,48$.

I07. Felski, "Introduction: Everyday Life," 2002, 607.

I08. Felski, "Introduction: Everyday Life," 2002, 607-6г2

Io9. Kuusito, Only Bread, Only Light: Poems, 2000, 27-28

IIo. Mintz, "Lyric Bodies: Poets on Disability and Masculinity,"

20I2, 249 .

III. Mintz, "Lyric Bodies: Poets on Disability and Masculinity," 20I2, 253 .

\section{REFERENCES}

Bayliss, Phil. "Against Interpretosis: Deleuze, Disability, and Difference." Journal of Literary and Cultural Studies 3.3 (2009): 28I-294. Project MUSE. Web. doi: Io.I353/ jlc. 0.0023 .

Bolt, David. The Metanarrative of Blindness: A Re-reading of Twentieth-century Anglophone Writing. Ann Arbor: The University of Michigan Press, 20I4. Web.

Couser, G. Thomas. "Disability, Life Narrative, and Representation." The Disability Studies Reader. Ed. Lennard J. Davis. New York: Routledge, 20I3. 456-459. Web.

Derrida, Jacques. "Signature Event Context." Limited Inc. Trans. Samuel Weber and Jeffrey Mehlman. Evanston, IL: Northwestern University Press, I988. I-22. Print.

Felski, Rita. "Introduction: Everyday Life." New Literary History. 33.4 (2002): 607-622. JSTOR. Web.

Freud, Sigmund. Totem and Taboo. Trans. James Strachey. New York: W.W. Norton, I989. Print.

Garland-Thomson, Rosemarie. Staring: How We Look. Oxford: Oxford University Press, 2009. Print.

Halberstam, Judith. "An Introduction to Female Masculinity." Female Masculinity. Durham, NC: Duke University Press, I998. Web. doi: I0.I2I5/9780822378II2-00I

Kleege, Georgina. Sight Unseen. New Haven: Yale University Press, I999.

Kleege, Georgina. "Blindness and Visual Culture: An Eyewitness Account." The Disability Studies Reader. Ed. Lennard J. Davis. New York: Routledge, 20I3. 448-455. Web. doi: IO.II77/I4704I2905054672

Kuusisto, Stephen. "Blind Days in Early Youth." Only Bread, Only Light: Poems. Port Townsend, WA: Copper Canyon Press, 2000. 5-7. Print.

Kuusisto, Stephen. "Guiding Eyes." Only Bread, Only Light: Poems. Port Townsend, WA: Copper Canyon Press, 2000. 20-2I. Print. 
Kuusisto, Stephen. Planet of the Blind. New York: Dial, I998. Print.

Melancon, Michael L. “"A River that No One Can See”: Body, Text, and Environment in the Poetry of Stephen Kuusisto." Journal of Literary \& Cultural Disability Studies I.2 (2009): I83-I94. Project MUSE. Web. doi: I0.1353/ jlc.0.00I9

Merleau-Ponty, Maurice. "The Intertwining-The Chiasm." The Visible and the Invisible. Trans. Alphonso Lingis. Evanston: Northwestern University Press, I968. I30-I55. Print.

Mintz, Susannah B. "Lyric Bodies: Poets on Disability and Masculinity.” PMLA. I27.2 (20I2): 248-263. Web. doi: I0.1632/pmla.20I2.127.2.248

Mitchell, David and Snyder, Sharon. "Narrative Prosthesis." The Disability Studies Reader. Ed. Lennard J. Davis. New York: Routledge, 2013. 222-235. Web. doi: IO.I2I5/0002983I-2006-0I8

Shakespeare, Tom. "The Sexual Politics of Disabled Masculinity." Sexuality and Disability. I7.I (I999): 53-64. Web. doi: I0.IO23/A:IO2I403829826

Shuttleworth, Russell P. “Disabled Masculinity: Expanding the Masculine Repertoire." Gendering Disability. New Brunswick, New Jersey: Rurgers University Press, 2004.

Siebers, Tobin. Disability Aesthetics. Ann Arbor: The University of Michigan Press, 2010. Print. 